\title{
Antidepressant, anxiolytic and anorectic effects of a melanin-concentrating hormone-1 receptor antagonist
}

\author{
Beth Borowsky, Margaret M. Durkin, Kristine Ogozalek, Mohammad R. Marzabadi, \\ John Deleon, Rainer Heurich, Harvey Lichtblau, Zoya Shaposhnik, Irena Daniewska, \\ Thomas P. Blackburn, Theresa A. Branchek, Christophe Gerald, Pierre J. Vaysse \& \\ CARLOS Forray
}

Synaptic Pharmaceutical Corporation, Paramus, New Jersey, USA

Correspondence should be addressed to C.F.; email: cforray@synapticcorp.com

Published online: 15 July 2002, doi:10.1038/nm741

\begin{abstract}
Melanin concentrating hormone $(\mathrm{MCH})$ is an orexigenic hypothalamic neuropeptide, which plays an important role in the complex regulation of energy balance and body weight. Here we show that SNAP-7941, a selective, high-affinity $\mathrm{MCH1}$ receptor (MCH1-R) antagonist, inhibited food intake stimulated by central administration of $\mathrm{MCH}$, reduced consumption of palatable food, and, after chronic administration to rats with diet-induced obesity, resulted in a marked, sustained decrease in body weight. In addition, after mapping the binding sites for $\left[{ }^{3} \mathrm{H}\right] \mathrm{SNAP}$ 7941 in rat brain, we evaluated its effects in a series of behavioral models. SNAP-7941 produced effects similar to clinically used antidepressants and anxiolytics in three animal models of depression/anxiety: the rat forced-swim test, rat social interaction and guinea pig maternal-separation vocalization tests. Given these observations, an MCH1-R antagonist may be useful not only in the management of obesity but also as a treatment for depression and/or anxiety.
\end{abstract}

Melanin-concentrating hormone $(\mathrm{MCH})$, a cyclic 19-aminoacid polypeptide, is produced predominantly by neurons in the lateral hypothalamus and zona incerta which project broadly throughout the brain ${ }^{1}$. Several lines of evidence implicate $\mathrm{MCH}$ as an important mediator in the regulation of energy balance and body weight. Central MCH administration stimulates food intake while fasting results in an increase in $\mathrm{MCH}$ expression ${ }^{2}$. Mice lacking the gene encoding $\mathrm{MCH}$ are lean, hypophagic and maintain elevated metabolic rates ${ }^{3}$. In contrast, mice overexpressing the $\mathrm{MCH}$ gene are susceptible to obesity and insulin resistance $^{4}$. Although these findings support a rationale for $\mathrm{MCH}$ antagonists in the treatment of obesity, it is unclear if sufficient $\mathrm{MCH}$ tone exists to produce a robust and sustained loss of body weight after chronic MCH-receptor blockade. Moreover, because genetic manipulation of the $\mathrm{MCH}$ gene also affects the expression of neuropeptide E-I and neuropeptide G-E, which are processed from the same prehormone precursor as $\mathrm{MCH}$, the observed phenotypes may be influenced by changes in the levels of these less characterized peptides ${ }^{5}$.

The effects of $\mathrm{MCH}$ are mediated through receptors in the rhodopsin superfamily of G protein-coupled receptors (GPCRs). $\mathrm{MCH} 1$ receptor (MCH1-R) has been isolated from rodents and humans ${ }^{6,7}$, whereas MCH2-R has thus far been identified only in humans ${ }^{8,9}$. To assess the role of MCH1-R, we identified a selective, high-affinity MCH1-R antagonist and evaluated it in several animal models. We report here that the acute administration of a MCH1-R antagonist attenuated central $\mathrm{MCH}$-stimulated food intake, and reduced consumption of palatable food. Moreover, chronic administration of this antagonist produced a robust and sustained decrease in body weight in rats with diet-induced obesity. As the distribution of MCH1-R binding sites in the central nervous system (CNS) is suggestive of a role for $\mathrm{MCH}$ in the regulation of mood and stress, we tested the MCH1-R antagonist in several animal models of depression and anxiety. Pharmacological blockade of the MCH1-R produced a profile similar to clinically used antidepressants and anxiolytics, suggesting that the MCH1-R might be a novel target for the treatment of depression and anxiety.

SNAP-7941 is a selective, high-affinity MCH1-R antagonist Screening of our GPCR-biased compound collection against the human MCH1-R in a functional assay measuring intracellular $\mathrm{Ca}^{2+}$ mobilization resulted in the discovery of a highpotency antagonist, SNAP-7941 ((+)-methyl (4S)-3-\{[(3-\{4-[3(acetylamino)phenyl]-1-piperidinyl\}propyl)amino]carbonyl $\}-4-$ (3,4-difluorophenyl)-6-(methoxymethyl)-2-oxo-1,2,3,4-tetrahydro-5-pyrimidinecarboxylate hydrochloride) (Fig. 1a). SNAP7941 is a competitive antagonist of $\mathrm{MCH}$ in a $\left[{ }^{3} \mathrm{H}\right]$ phosphoinositide accumulation assay in a mammalian cell line expressing the human MCH1-R (Fig. $1 b$ ). The Schild regression from these data estimated a $\mathrm{pA}_{2}$ of 9.24 with a slope of $0.98\left(\mathrm{r}^{2}=\right.$ 0.94 ) for SNAP-7941 (Fig. $1 b$, inset), which predicts a $K_{\mathrm{b}}$ of 0.57 $\mathrm{nM}$. This compound was greater than 1,000-fold selective for MCH1-R compared with the human MCH2-R, as well as GPCRs associated with food intake including $5-\mathrm{HT}_{2 \mathrm{c}}$, galanin and neuropeptide Y (NPY). SNAP-7941 also proved to be suitable for use as a tritiated radioligand. Analysis of saturation isotherms revealed a measured $K_{\mathrm{d}}$ of $0.18 \mathrm{nM}$ with specific binding of $98 \%$ in COS-7 cells expressing human MCH1-R (Fig. 1c). The binding of $\left[{ }^{3} \mathrm{H}\right] \mathrm{SNAP}-7941$ was displaced by $\mathrm{MCH}$ with a $K_{\mathrm{i}}$ of $15 \pm 0.11 \mathrm{nM}$ (Fig. 1d), consistent with its potency to elicit a functional response in the same cell line (Fig. $1 b$ ). 
$a$<smiles>COC(=O)C1=C(CO[N+](=O)[O-])NC(=O)N(C(=O)NCCCN2CCC(c3cccc(NC(C)=O)c3)CC2)C1c1ccc(F)c(F)c1</smiles>

$b$

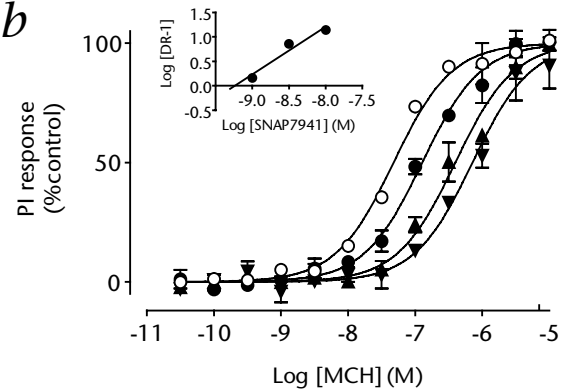

Fig. 1 SNAP-7941 is a high-affinity antagonist ligand for MCH-1R. $\boldsymbol{a}$, Chemical structure of SNAP7941 ((+)-methyl (4S)-3-\{[(3-\{4-[3-(acetylamino)phenyl]-1-piperidinyl\}propyl)amino]carbonyl\}-4(3,4-difluorophenyl)-6-(methoxymethyl)-2-oxo-1,2,3,4-tetrahydro-5-pyrimidinecarboxylate hydrochloride). $\boldsymbol{b}$, Antagonism by SNAP-7941 $(\boldsymbol{\bullet}, 1 \mathrm{nM}),(\boldsymbol{\Lambda}, 3 \mathrm{nM}),(\boldsymbol{\nabla}, 10 \mathrm{nM})$ of the activation of $\left[{ }^{3} \mathrm{H}\right]$ phosphoinositide metabolism ( $\left.\mathrm{PI}\right)$ elicited by $\mathrm{MCH}(\mathrm{O}$, control) in COS-7 cells expressing the recombinant human MCH1-R. Data are mean \pm s.e.m., $n=3$. Inset, Schild plot. DR, dose ratio calculated from $\mathrm{EC}_{50}$ values from concentration response curves. c, Binding of $\left[{ }^{3} \mathrm{H}\right] \mathrm{SNAP}-7941$ to membranes from COS-7 cells expressing human MCH1-R in the absence $(O)$ or presence $(\mathbf{\Delta})$ of 10 $\mu \mathrm{M}$ SNAP-7941. Data are mean \pm s.e.m., $n=3$. Inset, Scatchard analysis of the specific binding $(\bullet)$ of $\left[{ }^{3} \mathrm{H}\right] \mathrm{SNAP}-7941 . K_{\mathrm{d}}=0.18 \mathrm{nM} ; \mathrm{B}_{\max }=870 \mathrm{fmol} / \mathrm{mg}$ protein. $\boldsymbol{d}$, Displacement of $\left.{ }^{3} \mathrm{H}\right] \mathrm{SNAP}-7941 \mathrm{bind}-$ ing to membranes of COS-7 cells expressing human MCH1-R, by MCH (O) or SNAP-7941 (๑).

C

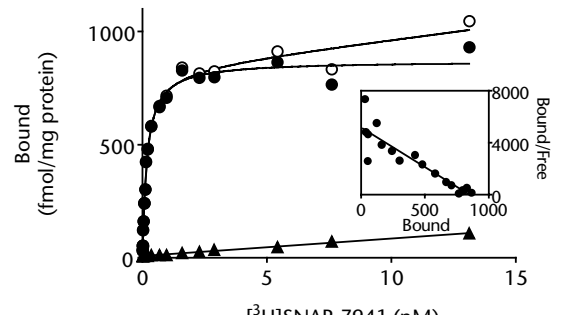

$\left[{ }^{3} \mathrm{H}\right] \mathrm{SNAP}-7941(\mathrm{nM})$

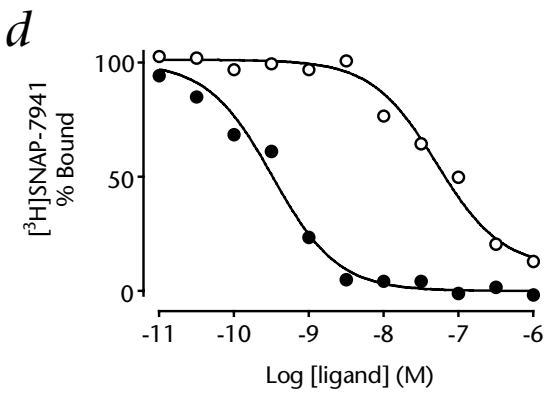

MCH1-Rs in rat brain were mapped using $\left[{ }^{3} \mathrm{H}\right] \mathrm{SNAP}-7941$ (Fig. $2 a-d$ ). Specific binding of $\left[{ }^{3} \mathrm{H}\right] \mathrm{SNAP}-7941$ was detected in the cerebral cortex, olfactory tubercle, claustrum and piriform cortex. $\left[{ }^{3} \mathrm{H}\right] \mathrm{SNAP}-7941$ binding sites were also present in several limbic structures, including the hippocampus, septum, nucleus of the diagonal band, bed nucleus of the stria terminalis and amygdala. Dense labeling by $\left[{ }^{3} \mathrm{H}\right]$ SNAP-7941 was found in brain regions rich in dopaminergic innervation such as the caudate-putamen and accumbens nucleus, with particularly intense labeling in the accumbens shell. Discrete $\left[{ }^{3} \mathrm{H}\right] \mathrm{SNAP}-7941$ binding sites were found throughout the hypothalamus with increased density in the ventromedial hypothalamus and the

$a$

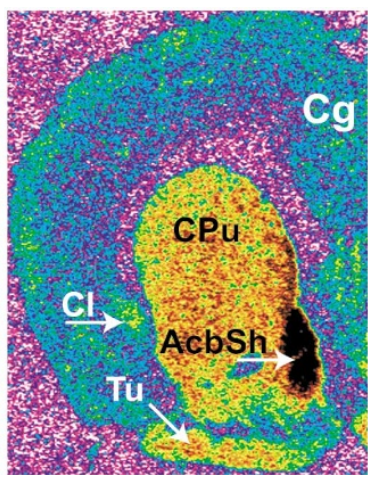

C

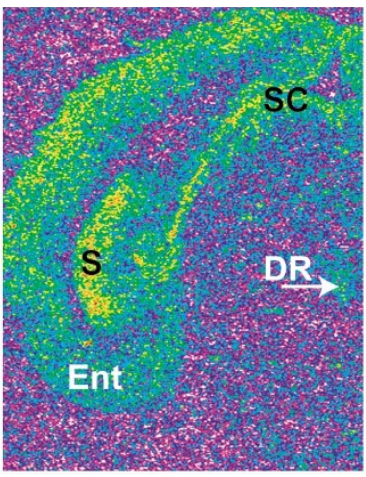

$b$

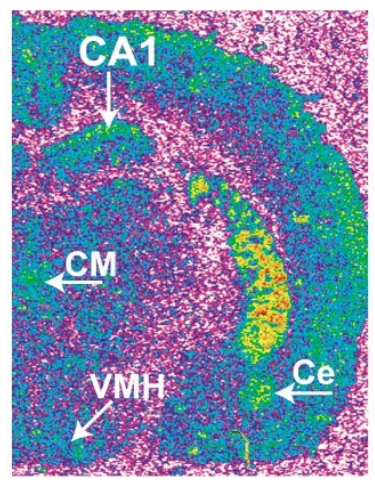

$d$

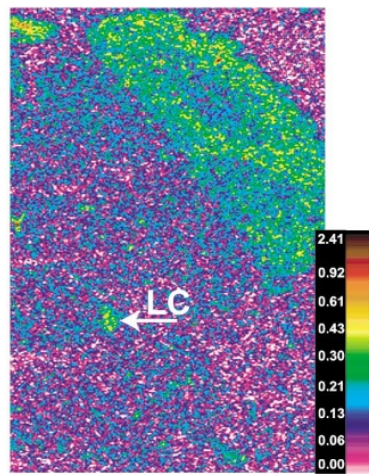

medial mammillary nucleus, as well as in the dorsal raphe and locus coeruleus. The distribution of $\left[{ }^{3} \mathrm{H}\right] \mathrm{SNAP}-7941$ binding sites parallels the distribution of both MCH1-R mRNA (refs. $6,7)$ and MCH1-R protein expression ${ }^{10}$, suggesting that SNAP7941 binds selectively to MCH1-R.

\section{SNAP-7941 is a centrally active anorectic compound}

To determine if the orexigenic effect of $\mathrm{MCH}$ is mediated by MCH1-R, we tested the effect of SNAP-7941 on MCH-stimulated food intake in rats. Systemic pretreatment with SNAP$7941(10 \mathrm{mg} / \mathrm{kg}$, i.p.) inhibited the increase in food intake elicited by $\mathrm{MCH}(3 \mathrm{nmol})$ injected into the third ventricle (Fig. 3a). Although this finding supports a role for central MCH1-Rs in mediating MCH-stimulated food intake, it is not known if pharmacological blockade of $\mathrm{MCH}$ receptors would alter basal body weight. To test this hypothesis, SNAP-7941 was administered twice a day for seven days to rats with free access to standard lab chow. Although all rats gained weight over the course of the study, rats treated with $10 \mathrm{mg} / \mathrm{kg}$ i.p. of SNAP7941 gained 26\% less weight compared with vehicle-treated rats (Fig. 3b). Thus, chronic pharmacological treatment with an MCH1-R antagonist decreases body weight gain in young growing rats.

\section{MCH1-R blockade decreases palatable food consumption}

As $\mathrm{MCH}$ affects both food intake and metabolism, the observed change in body weight following MCH1-R antagonist treatment could be attributed to a reduction in food consumption, an increase in metabolic rate or both. To evaluate the ef-

Fig. 2 Pseudocolor photomicrographs showing the specific binding of $\left[{ }^{3} \mathrm{H}\right.$ ]SNAP-7941 in coronal rat brain sections (shown in hemisection). a-d, The distance (in $\mathrm{mm}$ ) from bregma is $+1.70(a),-2.30(b),-7.64(c)$ and -9.30 (d) (ref. 25). AcbSh, accumbens nucleus, shell; CA1, field CA1 of Ammon's horn; $\mathrm{Ce}$, central amygdaloid nucleus; $\mathrm{Cg}$, cingulate cortex; $\mathrm{Cl}$, claustrum; $\mathrm{CM}$, central medial thalamic nucleus; $\mathrm{CPu}$, caudate-putamen; DR, dorsal raphe; Ent, entorhinal cortex; LC, locus coeruleus; S, subiculum; SC, superior colliculus; Tu, olfactory tubercle; $\mathrm{VMH}$, ventromedial hypothalamus. Scale bar in $d$ indicates the relative optical density. 


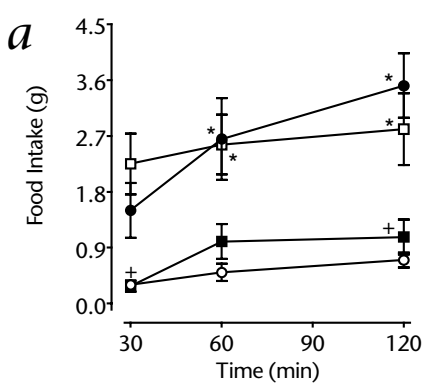

$b$

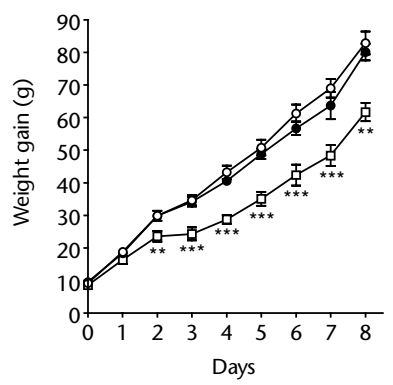

Fig. 3 SNAP-7941 decreases food intake and body weight in rats. $a$, Injections of $3 \mathrm{nmol} \mathrm{MCH}(\bullet, n=12)$ into the 3 rd ventricle increase food intake when compared with vehicle $(O, 5 \mu \mathrm{l} ; n=12) .{ }^{*}, P<0.05$. Systemic administration of SNAP-7941 (10 mg/kg i.p.) inhibits food intake elicited by $\mathrm{MCH}(\square, n=6)$; significantly different $(+, P<0.05)$ than i.p. vehicle $(\square ; n=$ $11)$. Each symbol represents mean \pm s.e.m. $\boldsymbol{b}$, Body weights of rats receiving 2 daily injections (days 1-7) of SNAP-7941 ( $\mathbf{\square}, 1 \mathrm{mg} / \mathrm{kg}$; curve not resolved from vehicle), $(\bullet, 3 \mathrm{mg} / \mathrm{kg}),(\square, 10 \mathrm{mg} / \mathrm{kg})$ or vehicle $(\bigcirc)$. Each

\section{C}
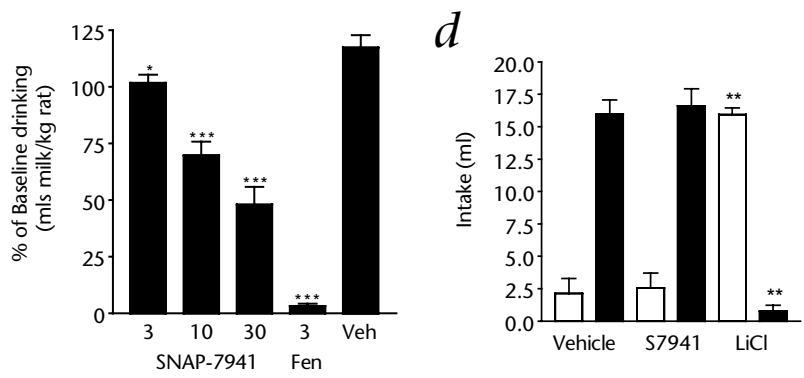

symbol represents mean \pm s.e. $m$; all groups $n=7 .{ }^{* *}, P<0.05 ; * * *, P<0.01$, significantly lower than vehicle. $\boldsymbol{c}$, Effect of SNAP-7941 $(3 \mathrm{mg} / \mathrm{kg}, n=5 ; 10$ $\mathrm{mg} / \mathrm{kg}, n=7$; or $30 \mathrm{mg} / \mathrm{kg}, n=6)$, D-fenfluramine ( $3 \mathrm{mg} / \mathrm{kg}, n=7$ ) or vehicle $(n=6)$ on sweetened condensed milk consumption in rats. ${ }^{*}, P<0.05$; ***, $P<0.01$, significantly lower than vehicle. $\boldsymbol{d}$, Effects of SNAP-7941 (10 $\mathrm{mg} / \mathrm{kg}$ i.p., $n=10), \mathrm{LiCl}(300 \mathrm{mg} / \mathrm{kg}$ i.p., $n=10)$ and vehicle $(n=10)$ on conditioned taste aversion in rats $\left(\square\right.$, water; $\mathbf{\square}$, saccharin). ${ }^{* *}, P<0.01$, significantly different from vehicle. fect of MCH1-R blockade on palatable food consumption, we tested the effect of SNAP-7941 on the drinking of sweetened condensed milk in satiated rats. In this model, $3 \mathrm{mg} / \mathrm{kg}$ of Dfenfluramine almost completely suppressed milk consumption (Fig. 3c). Acute administration of SNAP-7941 produced a dose-dependent decrease in milk consumption (Fig. 3c). Rats treated with 3,10 and $30 \mathrm{mg} / \mathrm{kg}$ of SNAP-7941 intraperitoneally (i.p.) consumed 13, 41 and 59\% less milk, respectively, than vehicle-treated rats. These results suggest that SNAP-7941 acts as an anorectic agent capable of decreasing consumption of palatable food. To test if the anorectic effect of SNAP-7941 was the result of malaise, we performed a conditioned taste aversion study. Neither SNAP-7941 $(10 \mathrm{mg} / \mathrm{kg}$, i.p.) nor vehicle changed the preference to drink a sweetened solution, whereas $\mathrm{LiCl}(300 \mathrm{mg} / \mathrm{kg}$, i.p.) elicited a robust taste aversion effect (Fig. 3d). This observation demonstrates that the anorectic effect of SNAP-7941 is not the result of malaise.

Effects of MCH1-R chronic blockade on diet-induced obesity Human obesity is associated with a difficulty in balancing food consumption in the presence of excess availability of highly palatable foods, and a decrease in physical activity. To $a$

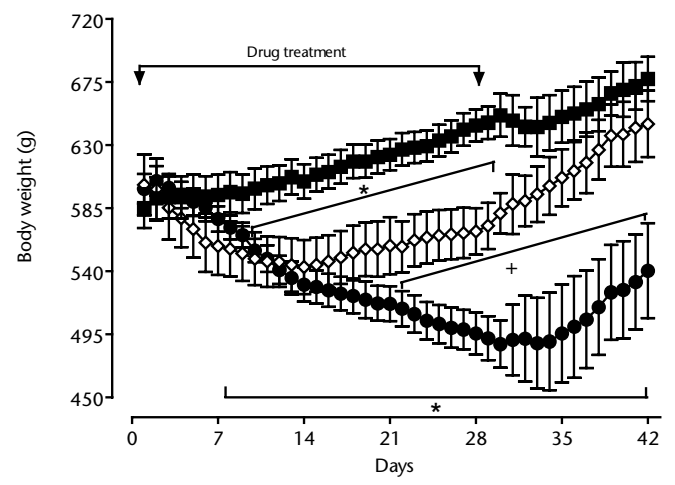

$b$

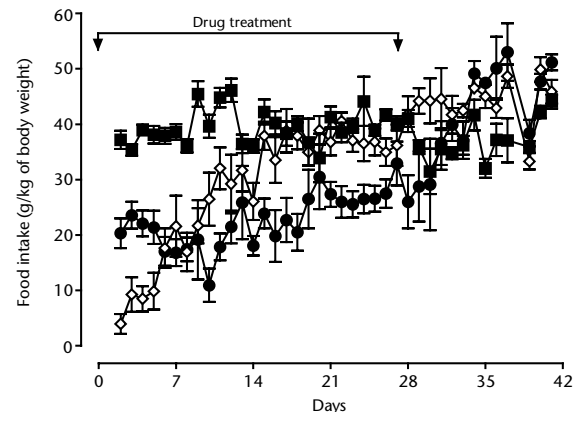

Fig. 4 SNAP-7941 decreases body weight and food intake in diet-induced obese rats. $\boldsymbol{a}$ and $\boldsymbol{b}$ Body weights (a) and daily food intake $(b)$ in diet-induced obese rats receiving 2 daily i.p. injections of vehicle $(\mathbb{\square}, n=7), 3 \mathrm{mg} / \mathrm{kg}$ D-fenfluramine, $(\diamond, n=6)$ or $10 \mathrm{mg} / \mathrm{kg} \operatorname{SNAP}-7941(\bullet, n=8) .{ }^{*}, P<0.05$; significantly different from vehicle. + , significantly different from $D$-fenfluramine $(P<0.05)$. $\boldsymbol{b}$, SNAP-7941 significantly different from vehicle $(P<0.05)$ for days 3-28. $d$-fenfluramine was significantly different from vehicle $(P<0.05)$ on days $2-14$ and 26. further assess the therapeutic potential of an MCH1-R antagonist in the management of human obesity, we tested the effects of SNAP-7941 in diet-induced obese (DIO) rats. Long-Evans rats were rendered obese by ad libitum exposure to a high-fat diet ( $45 \%$ of calories from fat). After 11 weeks, these rats weighed $592.2 \pm 9.3 \mathrm{~g}$ (from a starting weight of $227 \pm 3.2$ $\mathrm{g})$, whereas rats fed a control diet (10\% fat) weighed $481.8 \pm$ $14.2 \mathrm{~g}$ (from a starting weight of $224.7 \pm 5.8 \mathrm{~g}$ ). For a 4 -week period beginning in week 12 , DIO rats, maintained on the high-fat diet, were injected i.p. twice daily with either 10 $\mathrm{mg} / \mathrm{kg}$ SNAP-7941, $3 \mathrm{mg} / \mathrm{kg}$ D-fenfluramine or vehicle. Whereas vehicle-treated rats ate consistently and continued to gain weight, rats treated with D-fenfluramine initially ate very little food and lost weight but then gradually increased their consumption and gained weight at a rate somewhat less than that of vehicle-treated controls (Fig. $4 a$ and $b$ ). By the end of the study, D-fenfluramine-treated rats weighed $14 \%$ less than vehicle-treated rats $(572.2 \pm 16.5 \mathrm{~g}$ versus $666.4 \pm 22.5 \mathrm{~g}$, respectively). In contrast, rats treated with SNAP-7941 continuously ate less and lost weight throughout the duration of treatment. At the end of the 4 -week treatment period, the SNAP-7941 -treated rats weighed $26 \%$ less than vehicle-treated rats $(492.3 \pm 15.7 \mathrm{~g}$ versus 666.4 $\pm 22.5 \mathrm{~g}$, respectively). Whereas acute treatment with D-fenfluramine had a more pronounced effect than SNAP-7941 on sweetened condensed milk or high-fat food consumption, chronic treatment with SNAP7941, but not D-fenfluramine, produced a sustained and consistent decrease in food consumption and body weight.

The reversibility of the effects of both D-fenfluramine and SNAP-7941 on food intake became evident in the two weeks following the termination of drug treatment. DIO rats previously treated with SNAP-7941 showed an increase in their 
weight gain and their food consumption became indistinguishable to that seen in controls (Fig. $4 a$ and $b$ ), consistent with a tonic stimulatory role of $\mathrm{MCH}$ in the homeostasis of energy balance and body weight. In a separate study, the continuous infusion of SNAP-7941 at $10 \mathrm{mg} / \mathrm{kg} / \mathrm{day}$ for 2 weeks to rats did not modify a panel of blood tests for hepatic and renal function (data not shown), ruling out toxic effects of this MCH1-R antagonist as a causal role for the reduction in weight gain and food intake.

Antidepressant and anxiolytic properties of SNAP-7941 Although MCH has been studied most extensively in relation to food intake and body weight, the distribution of MCH1-R immunoreactivity ${ }^{10}$ and $\left[{ }^{3} \mathrm{H}\right]$ SNAP-7941 binding sites in areas such as the amygdala, accumbens nucleus, dorsal raphe and locus coeruleus suggest a possible role for $\mathrm{MCH}$ in mood regulation and anxiety. To further investigate this, SNAP-7941 was evaluated in three behavioral paradigms predictive of antidepressant and/or anxiolytic activity.

Clinically used antidepressants decrease the amount of time mice or rats spend immobile in the forced-swim test $\mathrm{t}^{11,12}$. Pretreatment of rats with a single oral dose of SNAP-7941 (3, 10 or $30 \mathrm{mg} / \mathrm{kg})$ or fluoxetine $(10 \mathrm{mg} / \mathrm{kg})$ significantly decreased the duration of immobility compared with vehicletreated controls, and increased the time these animals spent swimming (Fig. 5a). The profile of SNAP-7941 in the rat forced-swim test is similar to that of clinically used antidepressants, indicating that $\mathrm{MCH} 1-\mathrm{R}$ receptor blockade may be a novel therapeutic modality for the treatment of depressive disorders.

The rat social-interaction test has been used as a model of social anxiety with ethological validity ${ }^{13,14}$. The degree of social behavior displayed by unfamiliar male rats when placed together in a neutral territory is influenced by the perceived level of anxiety, and can be enhanced by pretreatment with anxiolytics such as chlordiazepoxide ${ }^{13,15}$. Acute treatment with 3,10 or $30 \mathrm{mg} / \mathrm{kg}$ SNAP-7941 or $5 \mathrm{mg} / \mathrm{kg}$ chlordiazepoxide significantly increased social interaction time compared with vehicle-treated controls without an overall increase in locomotor activity (Table 1). The response to the two lower doses of SNAP7941 was as robust as the response to $5 \mathrm{mg} / \mathrm{kg}$ chlordiazepoxide. In comparison, the antidepressant/anxiolytic paroxetine has been reported to increase social interaction in rats following chronic but not acute treatment ${ }^{15}$. The profile of SNAP7941 in the rat social-interaction test suggests that it may have anxiolytic activity as robust and as potent as chlordiazepoxide and with a more rapid onset of action than paroxetine.

Table 1 Effects of SNAP-7941 in the social-interaction test

\begin{tabular}{lcc} 
Treatment & $\begin{array}{c}\text { Social interaction } \\
(\mathrm{sec})\end{array}$ & $\begin{array}{c}\text { Locomotor activity } \\
\text { (squares crossed) }\end{array}$ \\
Vehicle & $102 \pm 6.1$ & $484 \pm 52$ \\
SNAP-7941, $3 \mathrm{mg} / \mathrm{kg}$ & $210 \pm 14^{* *}$ & $327 \pm 24^{*}$ \\
SNAP-7941, $10 \mathrm{mg} / \mathrm{kg}$ & $215 \pm 15^{* *}$ & $480 \pm 46$ \\
SNAP-7941, 30 mg/kg & $166 \pm 11^{* *}$ & $490 \pm 29$ \\
Chlordiazepoxide, $2 \mathrm{mg} / \mathrm{kg}$ & $228 \pm 11^{* *}$ & $355 \pm 49$ \\
\hline
\end{tabular}

Data are expressed as mean \pm s.e.m. Significantly different from vehicle: ${ }^{*}, P<0.05$; ${ }^{* *}$, $P<0.01 ; n=10$ for all groups.
Guinea pig pups separated from their mothers emit high frequency vocalizations that can be reduced by pretreatment with clinically active anxiolytics and antidepressants ${ }^{16-18}$. This model is an attractive complement to the two previous behavioral models because it relies on a decrease in stress-induced activity (vocalization) as opposed to an increase in overt behavioral activity (swimming or interaction). Acute treatment with 10 or $30 \mathrm{mg} / \mathrm{kg}$ SNAP-7941 or $2 \mathrm{mg} / \mathrm{kg}$ buspirone significantly reduced the number of vocalizations by guinea pig pups during a 5-minute separation from their mother (Fig. $5 b$ ). The responses to the two higher doses of SNAP-7941 were as robust as the response to buspirone. The general locomotor status of pups, as assessed by the righting reflex and the inclined board test, was determined to be similar to control animals (data not shown).

\section{Discussion}

We have discovered a highly selective and potent MCH1-R antagonist and used it to study the behavioral effects of pharmacological antagonism of the MCH1-R. The robust and sustained decrease in food intake and body weight in normal as well as diet-induced obese rats following treatment with SNAP-7941 supports previous evidence of a role for MCH in the regulation of body weight. Moreover, it demonstrates that there is sufficient $\mathrm{MCH}$ drive in mammals, without apparent compensatory mechanisms, to render MCH1-R a viable target for the treatment of obesity. The robust decrease in palatable food intake along with the distribution of MCH1-R in the limbic system suggest that the anorectic effects of an MCH1-R antagonist may be mediated by both direct hypothalamic inputs and a motivational component influencing the hedonic aspect of eating. Our data, although internally consistent, cannot rule out a contribution of increased energy expenditure on the reduction of body weight observed after MCH1-R blockade. The evidence that MCH increases the synthesis and secretion of leptin by adipocytes ${ }^{19}$ suggests the existence of additional inputs mediated by $\mathrm{MCH}$ receptors into the regulation of food intake and energy balance. However, the role of leptin is complex, as it might have a permissive role on the central actions of $\mathrm{MCH}$ by increasing the expression of $\mathrm{MCH} 1-$ $\mathrm{R}$ in the hypothalamus ${ }^{20}$. Further studies of these questions, as well as the metabolic and hormonal changes after chronic 
blockade of MCH1-R, will yield insight into the potential of this therapeutic approach in reversing the pathophysiological consequences of obesity.

The convergence of positive results for SNAP-7941 in three qualitatively different models for depression/anxiety and in two different species provides strong support for a role for $\mathrm{MCH}$ in the regulation of mood. Our present findings are in agreement with the anxiogenic effects of $\mathrm{MCH}$ infusion to the medial preoptic area in rats $^{21}$, and appear to contradict another report demonstrating an anxiolytic response to novelty following intracerebroventricular injection of $\mathrm{MCH}$ (ref. 22). A possible explanation for this discrepancy is the heterogeneous distribution in the brain of exogenously applied $\mathrm{MCH}$. Although the role of $\mathrm{MCH}$ in human psychiatric disorders remains largely unknown, we demonstrate for the first time the potential use of MCH1-R antagonists in the treatment of depression and/or anxiety.

\section{Methods}

Drugs. SNAP-7941 was synthesized at Synaptic Pharmaceutical Corporation and D-fenfluramine was purchased from Sigma. $\left[{ }^{3} \mathrm{H}\right] \mathrm{SNAP}$ 7941 was prepared by labeling the piperidine ring from an advanced unsaturated intermediate (Amersham Biosciences, Cardiff, Wales).

In vitro functional activity and binding of SNAP-7941. Cos-7 cells transfected with the human MCH1-R receptor using the DEAE-dextran method ${ }^{23}$, were incubated in the presence of $\left[{ }^{3} \mathrm{H}\right] m$-inositol $(1 \mathrm{mCi} / \mathrm{ml})$ for $18 \mathrm{hr}$. The accumulation of $\left[^{3} \mathrm{H}\right]$ inositol phosphates was measured as described $^{24}$. Binding assays were performed incubating membranes isolated from cells expressing the $\mathrm{MCH} 1-\mathrm{R}$ with varying concentrations of $\left[{ }^{3} \mathrm{H}\right] \mathrm{SNAP}-7941$ in binding buffer $(50 \mathrm{mM}$ Tris, $10 \mathrm{mM} \mathrm{MgCl}, 0.16 \mathrm{mM}$

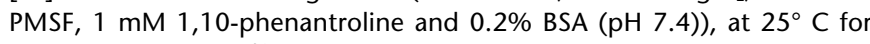
$90 \mathrm{~min}$, as described ${ }^{24}$.

In situ binding of $\left[{ }^{3} \mathrm{H}\right]$ SNAP-7941. Brain sections from adult male Sprague-Dawley rats were incubated at $25^{\circ} \mathrm{C}$ for $1.5 \mathrm{~h}$ in the binding buffer (see above) in the presence of $100 \mu \mathrm{M}$ dopamine, $1 \mu \mathrm{M}$ prazosin and $0.1 \mathrm{nM}\left[{ }^{3} \mathrm{H}\right] \mathrm{SNAP}-7941(56 \mathrm{Ci} / \mathrm{mmol})$. Specific binding was determined by subtracting the image resulting from tissue slides incubated with $\left[{ }^{3} \mathrm{H}\right] \mathrm{SNAP}-7941$ in the presence of $100 \mu \mathrm{M} \mathrm{MCH}$, from the image obtained in the absence of $\mathrm{MCH}$. Sections were washed in $4^{\circ} \mathrm{C} 50 \mathrm{mM}$ Tris-buffer, dipped in $4^{\circ} \mathrm{C}$ distilled water, dried under a stream of cold air and apposed to Hyperfilm- ${ }^{3} \mathrm{H}$ (Amersham, Piscataway, New Jersey) for 6 wk.

Effects of SNAP-7941 upon feeding elicited by MCH in the third ventricle. Male Wistar rats (180-200 g, Charles River, Portage, Michigan) were housed individually and maintained on 12-h light/dark cycle with lights on at 06:00, and given free access to standard rat chow (Purina Mills, Saint Louis, Missouri) and water. Stainless steel cannulae were implanted stereotaxically and aimed at the third ventricle under general anesthesia, $10 \mathrm{~d}$ before behavioral testing. Animals were habituated to the testing paradigm, pre-tested for two consecutive days by injecting $5 \mu \mathrm{l}$ artificial CSF into the cannula, and the amount of food consumed assessed after 30,60 and $120 \mathrm{~min}$. SNAP-7941 or its vehicle (1\% DMSO) was injected i.p. 10 min prior to $3^{\text {rd }}$ ventricle injection of $\mathrm{MCH}$ or its vehicle $(5 \mu$ artificial CSF). This study was performed at the Department of Psychology, at Queens College (CUNY, New York), under a protocol approved by the Queens College Institutional Animal Care and Use Committee.

7-day body-weight study. Male Long-Evans rats (180-200 g at start of experiment, Charles River) were housed in groups of 4 , maintained on 12 $\mathrm{h}$ light/dark cycle with lights on at 06:00, and given free access to standard rat chow (\#5012; fat percentage, 10\% kcal; Purina Mills) and water. SNAP-7941 or vehicle $(0.01 \%$ lactic acid, $\mathrm{pH} 6 ; 1 \mathrm{ml} / \mathrm{kg})$ was administered i.p. $2 \mathrm{~h}$ after lights on and $1 \mathrm{~h}$ before lights out.

Sweetened condensed milk study. Male Sprague-Dawley rats (180-200 $\mathrm{g}$, Charles River) were housed as above. For $20 \mathrm{~min}$ a day (2-5 $\mathrm{h}$ into the light cycle) for $7 \mathrm{~d}$, rats were placed in individual cages and allowed to drink sweetened condensed milk (Nestle, Glendale, California, diluted 1:3 with water). On the test day, rats received SNAP-7941, D-fenfluramine or vehicle $(0.01 \%$ lactic acid $(\mathrm{pH} 6) ; 1 \mathrm{ml} / \mathrm{kg}$ ) was administered i.p. $30 \mathrm{~min}$ before having access to milk. The amount of milk consumed was compared with the baseline consumption for each rat determined on the previous $3 \mathrm{~d}$.

Conditioned taste aversion test. Groups of 10 rats were randomly assigned to three groups and accustomed to a $1-\mathrm{h}$ drinking period per day $(5 \mathrm{~d})$ of tap water. On experimental day 6 , a $0.1 \%$ aqueous solution of saccharin was presented to each rat and the volume consumed was recorded. 15 min after bottle removal, rats were injected i.p. with either vehicle $(0.01 \%$ lactic acid $(\mathrm{pH} 6))$, SNAP-7941 $(10 \mathrm{mg} / \mathrm{kg})$ or $\mathrm{LiCl}(300 \mathrm{mg} / \mathrm{kg})$. During the following $5 \mathrm{~d}$, each rat was offered both water and saccharin in separate bottles for their $1-\mathrm{h}$ drinking session. This study was performed by PsychoGenics Inc. (Hawthorne, New York).

Generation and testing of DIO rats. Male Long-Evans rats (Charles River) were housed individually, maintained on 12-h reverse light/dark cycle with lights off at 09:00, and given free access to either a high-fat diet (\#D12451; fat percentage, 45\% kcal; Research Diets, New Brunswick, New Jersey) or a control diet (\#D12450B; fat percentage, $10 \% \mathrm{kcal}$; Research Diets) and water. After $11 \mathrm{wk}$, rats on the high-fat diet began receiving SNAP-7941, D-fenfluramine or vehicle by i.p. injection twice daily, $1 \mathrm{~h}$ before lights off and $10 \mathrm{~h}$ later, for $4 \mathrm{wk}$. This study was performed at MPI Research (Mattawan, Michigan).

Rat forced-swim test. The procedure used here was similar to that described $^{12}$, with the following modifications. Male Sprague-Dawley rats (150-175, 4 g, from Taconic Farms, New York) were used for all experiments. Swim sessions were conducted for $5 \mathrm{~min}$, by placing rats in a plexiglass cylinder $(46 \mathrm{~cm}$ tall $\times 20 \mathrm{~cm}$ in diameter) filled $30-\mathrm{cm}$ deep with tap water at $23-25^{\circ} \mathrm{C}$. At this depth, rats were prevented from supporting themselves by touching the bottom of the cylinder. SNAP-7941, fluoxetine or vehicle $(0.01 \%$ lactic acid, $\mathrm{pH} 6)$ were administered orally as a 1 $\mathrm{ml} / \mathrm{kg}$ solution. All test sessions were videotaped and recorded for later scoring by a single rater, who was blinded to the treatment condition. Immobility was scored as the time a rat remained floating in the water making only movements necessary to keep its head above the water. Swimming was scored as the time a rat made active swimming motions, more than necessary to merely maintain its head above water. This study was performed at Thera Search Laboratories (Miller Place, New York).

Rat social-interaction test. The rat social-interaction test was performed for $15 \mathrm{~min}$ as described ${ }^{13}$ under low-light conditions using pairs of unfamiliar male Sprague-Dawley rats (200-230 g, Taconic Farms) previously housed singly and exposed to the test arena for $15 \mathrm{~min}$ on the previous day. SNAP-7941, chlordiazepoxide or vehicle $(0.01 \%$ lactic acid $(\mathrm{pH} 6))$ were injected i.p. as a $1 \mathrm{ml} / \mathrm{kg}$ solution. All test sessions were videotaped and recorded for later scoring. Active social interaction, defined as sniffing, grooming, biting, boxing and crawling over and under, as well as locomotor activity (defined as squares crossed), was scored by a single rater, who was blinded to the treatment of each pair. This study was performed at Thera Search Laboratories.

Guinea pig maternal-separation vocalization test. 2-wk-old pups, prescreened for vocalization, received an i.p. injection of SNAP-7941, buspirone or vehicle $(0.01 \%$ lactic acid, $\mathrm{pH} 6)$ as a $1 \mathrm{ml} / \mathrm{kg}$ solution and were returned to their mothers for $1 \mathrm{~h}$. Individual pups were then placed in the test chamber and the number of vocalizations was counted over a 5-min period. Each pup was tested twice with a 3-d rest period. To assess effects of the test drugs on sedation or general motor impairment, after the second separation test, pups were placed on an inclined board and the angle at which the pup braced itself was determined. In addition, pups were placed on their backs and the latency to right themselves was measured. This study was performed at NeuroDetective Inc. (Quakertown, Pennsylvania).

Statistical analysis. For the antagonism of $\mathrm{MCH}$-induced feeding study (Fig. 3a), one-way repeated measures ANOVA was performed, with Tukey 
corrected comparisons. For the 1- (Fig. 3b) and 4-week (Fig. 4a and $b$ ) body-weight experiments, overall results were analyzed by 2-way ANOVA and data for each time-point were analyzed by one-way ANOVA followed by post hoc Student-Newman-Keuls test. For the sweetened condensed milk study (Fig. 3c), swim test (Fig. 5a), social interaction (Table 1) and maternal separation studies (Fig. $5 b$ ), data were analyzed by one-way ANOVA followed by post hoc Student-Newman-Keuls or Fisher's LSD test.

\section{Acknowledgments}

We thank T. Johnson-Blake, S. Kokkinakis and Z. Wang for technical support;

M. Walker, J. Wetzel and D. Craig for discussions; R.J. Bodnar, C. Ashby Jr, C. Struble and B. Olivier for collaborative studies.

\section{Competing interests statement}

The authors declare competing financial interests: see the website (http://medicine.nature.com) for details.

\section{RECEIVED 7 MAY; ACCEPTED 18 JUNE 2002}

1. Bittencourt, J.C. et al. The melanin concentrating hormone system of the rat brain: an immuno-histochemical characterization. J. Comp. Neurol. 319, 218-245 (1992).

2. Qu, D. et al. A role for melanin-concentrating hormone in the central regulation of feeding behaviour. Nature 380, 243-247 (1996).

3. Shimada, M., Tritos, N.A., Lowell, B.B., Flier, J.S. \& Maratos-Flier, E. Mice lacking melanin-concentrating hormone are hypophagic and lean. Nature 396, 670-674 (1998)

4. Ludwig, D.S. et al. Melanin-concentrating hormone overexpression in transgenic mice leads to obesity and insulin resistance. J. Clin. Invest. 107, 379-386 (2001).

5. Nahon, J.L., Presse, F., Bittencourt, J.C., Sawchenko, P.E. \& Vale, W. The rat melanin-concentrating hormone messenger ribonucleic acid encodes multiple putative neuropeptides coexpressed in the dorsolateral hypothalamus. Endocrinol. 125, 2056-65 (1989).

6. Sato, Y. et al. Molecular characterization of the melanin-concentrating-hormone receptor. Nature 400, 265-269 (1999).

7. Chambers, J. et al. Melanin-concentrating hormone is the cognate ligand for the orphan G protein-coupled receptor SLC-1. Nature 400, 261-265 (1999).
8. Hill, J. et al. Molecular cloning and functional characterization of $\mathrm{MCH}_{2}$, a novel human MCH receptor. J. Biol. Chem. 276, 20125-20129 (2001).

9. Sailer, A.W. et al. Identification and characterization of a second melanin-concentrating hormone receptor, MCH-2R. Proc. Nat. Acad. Sci. USA 98, 7564-7569 (2001).

10. Hervieu, G.J. et al. The distribution of the mRNA and protein products of the melanin-concentrating hormone $(\mathrm{MCH})$ receptor gene, slc-1, in the central nervous system of the rat. Eur. J. Neurosci. 12, 1194-1216 (2000).

11. Porsolt, R.D., Bertin, A. \& Jalfre, M. Behavioral despair in mice: A primary screening test for antidepressants. Arch Int Pharmacodyn Ther. 229, 327-336 (1977)

12. Lucki, I., Dalvi, A. \& Mayorga, A.J. Sensitivity to the effects of pharmacologically selective antidepressants in different strains of mice. Psychopharmacology 155, 315-322 (2001).

13. File, S.E. \& Hyde, J.R.G. Can social interaction be used to measure anxiety? Br. I. Pharmacol. 62, 19-24 (1987)

14. Rodgers, R.J., Cao. B.J., Calvi, A. \& Holmes, A. Animals models of anxiety: An ethological perspective. Braz. J. Med. Biol. Res. 30, 289-304 (1977).

15. Lightowler, S., Kennett, G.A., Williamson, I.J.R., Blackburn, T.P. \& Tulloch, I.F. Anxiolytic-like effect of paroxetine in a rat social-interaction test. Pharmacol. Biochem. Behav. 49, 281-285 (1994).

16. Pettijohn, T.F. Effects of imipramine on infant guinea pig distress vocalization. Psychological Reports. 44, 918 (1979).

17. Pettijohn, T.F. Attachment and separation distress in the infant guinea pig. Devel. Psychobiol. 12, 73-81 (1979).

18. Kramer, M.S. et al. Distinct Mechanism for Antidepressant Activity by blockade of central substance P receptors. Science 281, 1640-1645 (1998).

19. Bradley, R.L., Kokkotou, E.G., Maratos-Flier, E. \& Cheatham, B. Melanin-concentrating hormone regulates leptin synthesis and secretion in rat adipocytes. Diabetes. 49, 1073-1077 (2000).

20. Kokkotou, E.G., Tritos, N.A., Mastaitis, J.W., Slieker, L., \& Maratos-Flier, E. Melanin-concentrating hormone receptor is a target of leptin action in the mouse brain. Endocrinol. 142, 680-686 (2001).

21. Gonzalez, M.I., Vaziri, S. \& Wilson, C.A. Behavioral effects of a-MSH and MCH alter central administration in the female rat. Peptides 17, 171-177 (1996).

22. Monzón, M.E. \& DeBarioglio, S.R. Response to novelty after i.c.v. injection of melanin-concentrating hormone $(\mathrm{MCH})$ in rats. Physiol. Behav. 67, 813-817 (1999).

23. Gerald, C. et al. Expression cloning and pharmacological characterization of a human hippocampal neuropeptide Y/peptide YY Y2 receptor subtype. J. Biol. Chem. 270, 26758-26761 (1995).

24. Bonini, J.A. et al. Identification and characterization of two $G$ protein-coupled receptors for neuropeptide FF. J. Biol. Chem. 275, 39324-39331 (2000).

25. Paxinos, G. \& Watson, C. in The Rat Brain in Stereotaxic Coordinates. (Academic, San Diego, California, 1998). 